\title{
Como será o cenário da Educação Superior em 2030? ${ }^{1}$
}

What will the higher education scenario look like in 2030?

\author{
Milena Pavan Serafim ${ }^{1}$ \\ ${ }^{1}$ Universidade Estadual de Campinas | Programa de Pós-Graduação Interdisciplinar em \\ Ciências Humanas e Sociais Campinas | SP | Brasil. \\ Contato: milenaps@unicamp.br \\ https://orcid.org/0000-0002-7541-4182
}

DOI: http://dx.doi.org/10.1590/S1414-40772019000300001

Este é um artigo publicado em acesso aberto sob uma licença Creative Commons https://creativecommons.org/licenses/by-nc/4.0/

Como será o cenário da Educação Superior em 2030? A resposta desta pergunta não é trivial. A única certeza é de que boa parte das predições aponta que o cenário será diferente. $\mathrm{O}$ quão diferente é a questão que devemos buscar conhecer. Para conhecer o cenário da educação superior, precisamos prospectar como será o contexto no qual ela se insere, no que se refere ao contexto social, tecnológico, econômico, político e de meio ambiente.

Uma hipótese levantada por vários estudos é que a adoção da machine learning, artificial intelligence, internet das coisas, Indústria 4.0 elou tecnologias disruptivas trará algum impacto no cenário da educação e do processo de ensino-aprendizagem e, claro, na formação de professores capazes de dar conta da rapidez com que os alunos aprenderão e reaprenderão, seja em áreas nas quais a interface com a tecnologia é mais evidente, seja em áreas que são impactadas pelo processo de construção sociotécnica e sua co-conformação da sociedade e da tecnologia neste cenário. Decorrente disso, o ambiente de trabalho, que já passa por transformações, será cada vez mais disruptivo.

Neste sentido, o ambiente de trabalho requererá o ensino superior a capacidade de adaptabilidade. $\mathrm{O}$ atual modelo de ensino, que se estrutura em instituições formais, que são acreditadas por órgãos estaduais e/ou federais e conselhos profissionais, terá a concorrência direta de outros modelos. O processo de aprendizagem que, no modelo atual, ocorre em ciclos definidos e rígidos de formação: graduação e pós-graduação, também ocorrerá por meio de escolas informais, como a Singularity University, bem como escolas que irão fornecer conteúdos focados em aprendizados rápidos e baratos para atuação imediata no mercado de trabalho (Universidades Corporativas). A necessidade frequente de capacitação dos trabalhadores, a destreza digital e o aprendizado contínuo serão valorizados.

\footnotetext{
${ }^{1}$ Em memória de Prof. Dr. Newton Cesar Balzan.
} 
O ponto apresentado pela hipótese é que o cenário disruptivo tensionará e criará modelos de educação diferenciados, que terá desde as instituições de ensino e pesquisa, que formarão integralmente o cidadão-profissional, com foco no desenvolvimento aprofundado de conhecimentos criativos, assim como as escolas fast-food, Educação Just-In-Time ou como alguns estão denominando Massive Online Open Courses (MOOCs), que fornecerão conteúdos rápidos e aplicados ao mercado de trabalho. Enquanto o primeiro modelo é elitizado e pouco includente, reforçando o padrão tradicional da universidade, o segundo é massificado e orientado ao mercado.

Assim, outras perguntas se colocam: Como conciliar os dois tipos de ensino que, em princípio, parecem antagônicos? A educação de forma integral enquanto bem público será garantido a todos? Haverá algum tipo de retrocesso nas políticas inclusivas de educação superior brasileira? Como garantir inovação se parte significativo de esforços será orientado a responder rapidamente demandas de formação específica de mercado? Qual ator financiará cada modelo?

Em contexto socioeconômico de profunda desigualdade, como o brasileiro, modelos tão dicotômicos como esses implicam no médio e longo prazo em um agravamento das assimetrias sociais e econômicas. Nas últimas duas décadas, foi possível visualizar membros de famílias que ingressaram pela primeira vez na Universidade Pública no Brasil. Isso pôde ser visto também em outros países, como os Estados Unidos, por exemplo. O efeito disso, para além do imediato e do passivo existente, está sendo visualizado, ainda que a passos lentos, em uma mudança na dinâmica regional.

Para compreender esses processos, Dias Sobrinho (2005, p. 164), ao analisar a interface entre o processo de globalização de mercados e o sistema universitário inserido nesse cenário, aponta que:

\footnotetext{
Nada em nosso tempo pode ser pensado sem que se levem em conta as características atuais da globalização. Tendo em vista que os esquemas simples de compreensão da realidade social são insuficientes para dar conta da complexidade e da pluralidade de sentidos dos fenômenos humanos, especialmente com a fragmentação e a multiplicação dos conhecimentos, das informações e dos intercâmbios, já não se pode pensar que uma instituição central da sociedade, radicalmente ligada às mudanças do mundo, como é o caso da universidade, possa ser explicada a partir de uma única ideia ou de um só princípio (p. 164).
}

Ainda que esse ponto seja relevante para não cair na armadilha da dicotomia construída até agora, reafirmar o papel da educação - sem pedagogismo ingênuo (BALZAN, 1994, p. 18) na ref. somente 2203 e 2008 - se faz necessário. Hoje, o modelo de universidade predominante padece em uma instituição fundamentada no paradigma da ciência positivista, com disciplinas isoladas e conteúdo fragmentado. A tecnologia produzida por essa mesma instituição conforma a sociedade para que, cada vez mais, esta tensione o conteúdo fragmentado. A realidade não se apresenta em disciplinas, ela é muito mais complexa e urgente. Assim, um elemento pacificado, mas urgente, se refere a necessidade das instituições de ensino superior reverem seus currículos. 
Sem pretensão de esgotar o debate, pelo contrário, buscando problematiza-lo ainda mais, recorro a alguns pensamentos do Prof. Dr. Newton Cesar Balzan ${ }^{2}$, um dos fundadores e apoiadores desta Revista, um dos grandes entusiastas e advogado da qualidade do ensino de graduação, em especial da formação de professores e da avaliação institucional, a quem homenageamos neste editorial pela sua trajetória e contribuição crítica aos estudos sobre Educação.

Dois elementos interessantes são explicitados. O primeiro é de que, sendo a educação, enquanto fenômeno educativo, variável dependente do quadro sócio-econômico-cultural, a inovação no ensino e no currículo não pode ser dissociada do próprio contexto no qual a educação se insere (BALZAN, 1994). O reflexo das mudanças ocorridas na sociedade até pode ter um certo atraso, mas sendo a educação parte desse processo, é inequívoco que elas serão incorporadas.

O segundo elemento importante, frente em especial ao debate se o professor será substituído pela máquina e sua inteligência artificial, Balzan (1994) aponta para a falácia sistemática de que a moderna tecnologia tornará a sala de aula um modelo pedagógico esgotado. Quando o Robô Pepper foi debater no Parlamento Inglês o futuro da inteligência artificial na educação, o debate entre a comunidade científica se acirrou. Alguns entusiastas rapidamente se posicionaram que a dinâmica em sala de aula mudaria significativamente, que o sistema educacional deveria incorporar as mudanças tecnológicas como algo inexorável, outros problematizaram que o processo de ensino-aprendizagem não é tão basilar. De qualquer forma, ambas as partes concordam que a centralidade do processo de ensinoaprendizagem é o estudante, que está em processo de formação multifacetada, que está além de apenas aprender um "ofício". Esse processo estaria ancorado na relação humana e inquieta entre professor e estudante.

Entretanto, Balzan (2003), em uma crítica feroz (que se coloca em uma atualidade inquestionável), aponta que, em um modelo de avaliação dominante que acomete as instituições de ensino superior, há pouco espaço e tempo para os docentes se aproximarem da inovação curricular, produção de saberes e conhecimentos.

Os ambientes estão pouco afeitos a um

os ambientes estão pouco afeitos a um retrato vivo e colorido de pessoas preocupadas em gerir relações sociais com seus alunos, conscientes da necessidade de fazer escolhas. Há espaços para a continuidade de iniciativas emancipatóriais, contra a corrente dominante? [...] O homem é por natureza inventivo e carrega a possibilidade da contradição. Penso que os espaços vêm sendo retirados em vez de ampliados (p. 157).

\footnotetext{
${ }^{2}$ Newton foi Assessor da Pró-Reitoria de Graduação da PUC-Campinas, foi Professor Titular da Faculdade de Educação da PUC-Campinas e Professor Aposentado - Colaborador Voluntário - da Faculdade de Educação da Universidade Estadual de Campinas. Foi professor da rede pública do Estado de São Paulo durante mais de 20 anos, docente da UNESP, USP, PUC-SP, Universidade Católica do Chile (Campus Villarrica). Tem doutorado em Ciências (Educação) e desenvolveu projeto em nível de pós-doutorado - Visiting Scholar- na Universidade de Boston, USA. Foi bolsista pesquisador nível 1-A junto ao CNPq.
} 
Neste sentido, finalizo o editorial agregando uma nova pergunta: Como estarão os professores universitários em 2030 ?

\section{Referências}

BALZAN, Newton César. Sete princípios inaceitáveis sobre a educação em países em desenvolvimento. Em Aberto, Brasília, v. 14, n. 64, p. 19-34, out./dez. 1994. Disponível em: http://emaberto.inep.gov.br/index.php/emaberto/article/view/1994/1963. Acesso em: 21 nov 2019.

BALZAN, Newton César. Inovação/visão única. Interface-Comunicação, Saúde, Educação, Botucatu, v. 7, p. 156-157, 2003. Disponível em:

http://www.scielo.br/pdf/icse/v7n13/v7n13a14.pdf. Acesso em: 21 nov 2019.

DIAS SOBRINHO, José. Educação superior, globalização e democratização: qual universidade?. Rev. Bras. Educ., Rio de Janeiro, n. 28, p. 164-173, jan. / abr. 2005. Dsiponível em: http://www.scielo.br/pdf/rbedu/n28/a14n28.pdf. Acesso em: 21 nov 2019. 